\title{
Echocardiographic measurement of the normal adult right ventricle
}

\author{
RODNEY FOALE, PETROS NIHOYANNOPOULOS, WILLIAM MCKENNA, \\ ANGELIKA KLIENEBENNE, ALEXANDER NADAZDIN, \\ EDWARD ROWLAND, * GILLIAN SMITH
}

From St Mary's Hospital and the Hammersmith Hospital, London

SUMMARY In studies of the right ventricle the complexities of chamber shape may be overcome by use of multiple tomographic imaging planes. An established protocol for the echocardiographic description of the heart was used to examine the right ventricle in an ordered series of transducer locations and orientations. Diastolic measurements were made of the right ventricular inflow tract, outflow tract, and right ventricular body, and the range and reproducibility of normal values for cavity size and right ventricular free wall thickness were established. These measurements of cavity size in 41 normal subjects were highly reproducible and the views that were used correctly described the truncated and ellipsoidal shape of the right ventricular inflow tract and body with a separately aligned outflow tract. Cavity trabeculation prevented measurement of the free wall thickness in some areas; however, values of nearly twice the previously reported upper limit of normal for anterior regions were measured from the apex or lateral right ventricular wall.

These normal data provide a basis for future echocardiographic studies of the right ventricle.

Evaluation of the structure of the right ventricle by available imaging methods presents a formidable problem. This is partly due to the complex geometry of the chamber, which has separate outflow and inflow portions and a main body which is crescentic and truncated. ${ }^{1}$ The right ventricular free wall also has a variable trabecular pattern that further limits precise measurement of cavity size and wall thickness. Additional factors, such as its retrosternal position and an anterior relation to the left heart that may vary according to the cardiac axis, make the right ventricle less accessible to the generally available diagnostic techniques whose orientation depends upon external landmarks. For example, the interpretation of studies of right ventricular function using technetium $99 \mathrm{~m}$ gated blood pool imaging may be limited by difficulties in separating the right ventricular blood pool signal from that of other cardiac chambers. ${ }^{2}$ Conventional contrast cineangiographic

Requests for reprints to Dr Rodney Foale, St Mary's Hospital, Praed Street, London W2 1NY.

${ }^{\star}$ Present address: National Heart Hospital, Westmoreland Street, London W1.

Accepted for publication 24 February 1986 assessment of the right ventricle fails to consider variations in chamber orientation in individual patients, and is further constrained by an inherent dependence upon a cavity silhouette made up by overlapping regions of the ventricular wall.

The use of tomographic methods that conventionally use a fixed transverse or sagittal orientation, such as nuclear magnetic resonance imaging, positron emission tomography, and computed tomographic scanning, is also limited in the evaluation of chamber shape, size, and wall thickness because their orientation depends on external landmarks. Thus, oblique cuts across an asymmetric right ventricular chamber obtained from transverse whole body image acquisition inevitably provide a cavity dimension and wall thickness measurements that are difficult to standardise between patients. Early $M$ mode echocardiographic studies of the right ventricle have necessarily relied upon an evaluation of a single dimension and wall thickness ${ }^{3}$ without consideration of the complex geometry of the chamber and the variable trabecular pattern of its wall.

The more recent development of cross sectional echocardiography has renewed interest in the examination of the right ventricle ${ }^{45}$ and offers the advan- 
tages of multiple tomographic views of the heart in a beat by beat display, without identifiable risk or discomfort to the patient. Furthermore, it may be that because with these methods reference to internal intracavitary landmarks is obligatory, right ventricular measurements obtained by echocardiography are more reliable that those obtained by techniques which image the right ventricular chamber without reference to peculiarities of internal structure or to its oblique orientation. To date, however, the approach to the cross sectional echocardiographic examination of the right ventricle has not been standardised.

We propose a systematic approach to the evaluation of the right ventricle with regard to its cavity size and measurement of its free wall thickness that may be easily used as part of a standardised echocardiographic examination protocol. The normal range of right ventricular cavity dimension and wall thickness taken from right ventricular projections in 41 subjects are provided, the reproducibility of the measurements is assessed, and the potential limitations of the technique are discussed.

\section{Subjects and methods}

The subjects were selected from healthy volunteers who were normal on clinical evaluation and who had a normal resting 12 lead electrocardiogram and chest $x$ ray. Technically adequate echocardiographic studies were used from 41 adult subjects aged from 19 to 46 years (mean 32 years). Twenty one were female and 20 male. Studies were considered to be of an adequate technical quality when the major part of the cavities of four cardiac chambers and each of four cardiac valves were identified both from the parasternal and from apical transducer locations.

Echocardiographic studies were performed by a high resolution cardiac ultrasound system with a 3.3 $\mathrm{MHz}$ transducer that was dynamically focused throughout the depth of the imaged field (GE Pass C,
International General Electric Company, Slough, Berkshire, UK). With this ultrasound system $M$ mode and cross sectional echocardiographic images may be simultaneously displayed and the $M$ mode beam may be positioned with reference to the cross sectional image. In this way accurate measurements along a known axis of the ventricle may be made. Each study was performed in accordance with a protocol modified at our hospital from that proposed by other groups. ${ }^{6-8}$ In this, images of the major and minor axes of each cardiac chamber were obtained in accordance with a strictly performed sequence outlined in Table 1. Each view is aligned according to internal reference points so that reproducible images of each cardiac chamber or their separate parts can be generated. In the course of this examination procedure specific right ventricular views are obtained, and it was from these and other views used in the protocol that right ventricular diastolic dimension and right ventricular free wall thickness were measured.

\section{RIGHT VENTRICULAR CHAMBER SIZE}

The three regions of the right ventricle were measured as follows:

\section{Right ventricular inflow tract}

Measurements of this region were obtained in four separate transducer orientations (Table 1).

Right ventricular inflow tract view-With the transducer in the third or fourth intercostal space at the left sternal edge, the long axis of the left heart was imaged with the interventricular septum and anterior aortic wall lying parallel to the chest wall. A shift in transducer position to a point approximately midway between the parasternal edge and cardiac apex with medial and downward tilt results in the ultrasound plane slipping across the sagittally orientated interventricular septum. Thus a view of the right ventricular inflow tract and right ventricular body in the major axis was obtained (Fig. 1). The region of

Table 1 Standardised echocardiographic examination sequence

\begin{tabular}{|c|c|c|}
\hline Transducer location & $\begin{array}{l}\text { Axis of chamber or } \\
\text { vessel }\end{array}$ & Views \\
\hline Left parasternal edge & $\begin{array}{l}\text { Major (or long) } \\
\text { Minor (or short) }\end{array}$ & 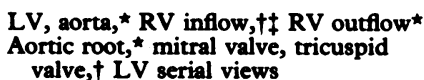 \\
\hline Cardiac apex & Major & $\begin{array}{l}\text { Four chamber } \$ \text { (left and right heart), } \\
\text { two chamber (left heart) }\end{array}$ \\
\hline Subcostal & Major & Four chamber, $\dagger$ LV serial views \\
\hline Suprasternal or upper sternal edge & $\begin{array}{l}\text { Major } \\
\text { Minor }\end{array}$ & $\begin{array}{l}\text { Aortic arch } \\
\text { Aortic arch }\end{array}$ \\
\hline
\end{tabular}

Views from which RV outflow tract, ${ }^{\star}$ inflow tract, $\dagger$ tricuspid valve annulus, $\ddagger$ and RV body $\S$ measurements were obtained. RV, right ventricle. 

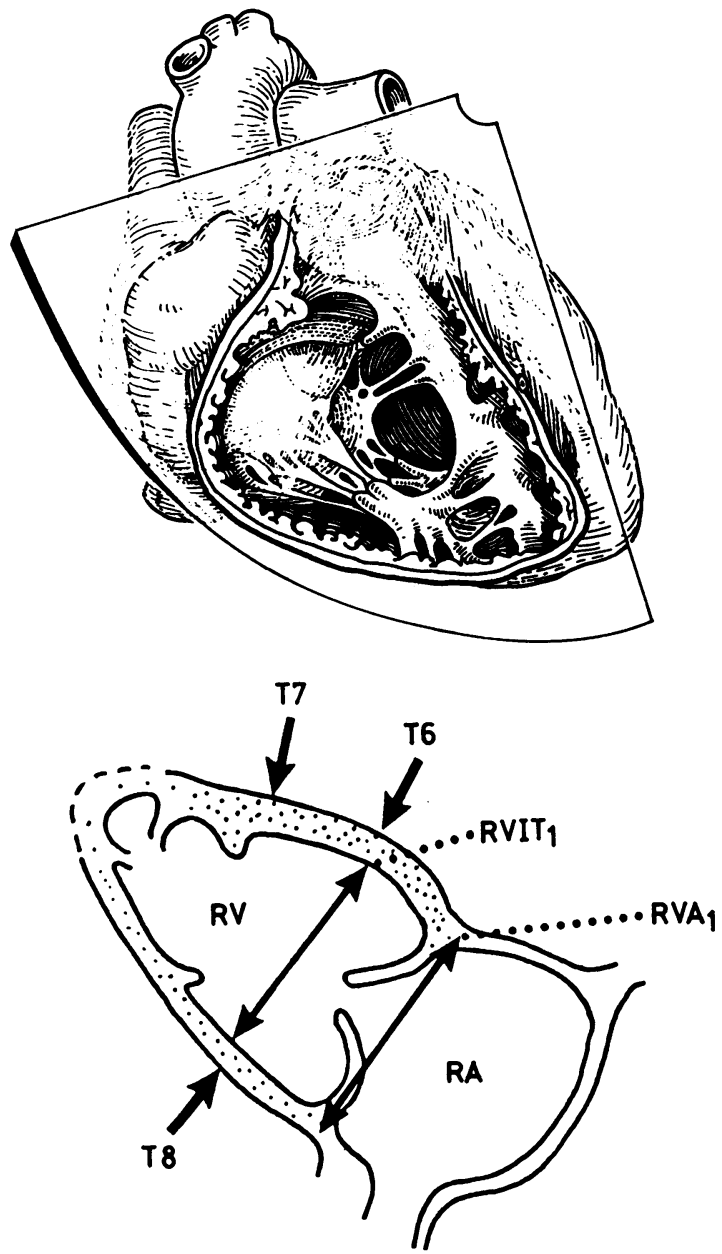

Fig. 1 Parasternal right ventricular inflow tract view. See text for measurements and abbreviations.

the right ventricular apex and the tricuspid valve annulus were used as the internal reference points as has been previously described, ${ }^{7}$ so that the inflow part of the right ventricle from the tricuspid annulus to at least the proximal right ventricular body was clearly defined. By scanning the ultrasound plane across the major axis of this region of the ventricle, maximum dimensions were measured of $(a)$ the tricuspid valve annulus $\left(\mathrm{RVA}_{1}\right)$, defined in this view as the region of the atrioventricular junction to which the anterior and posterior tricuspid valve leaflets attach and (b) the major axis of the right ventricular inflow tract (RVIT $)$, a measurement taken within one third of the distance below the annulus towards the region of the right ventricular apex. Care was
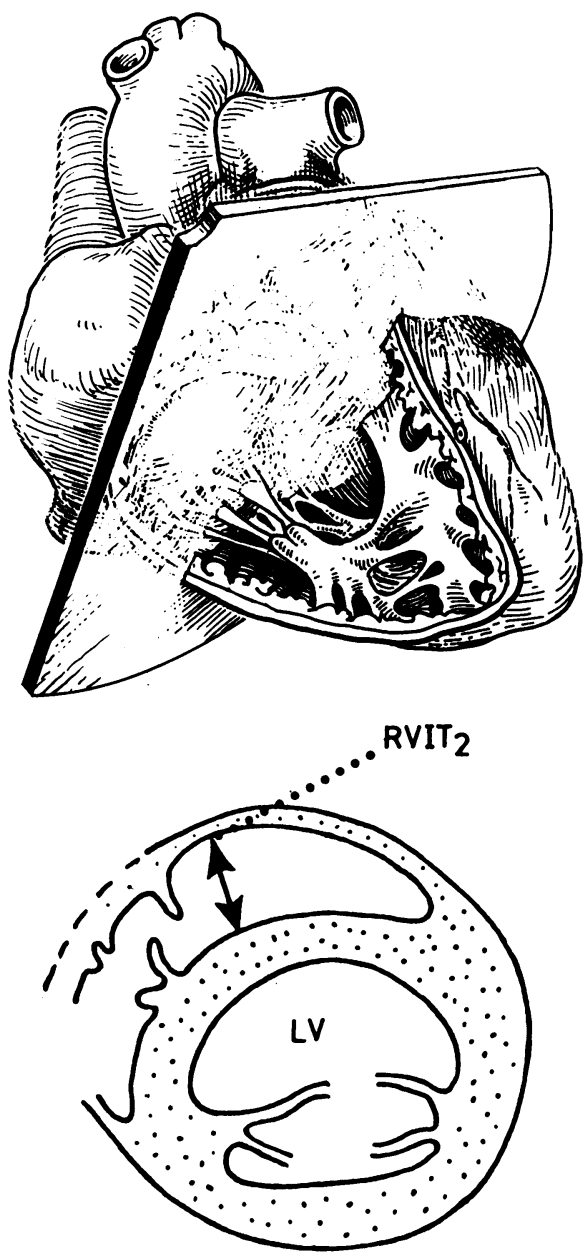

Fig. 2 Parasternal tricuspid valve short axis view. See text for measurements and abbreviations.

taken to exclude the proximal right ventricular outflow tract from this view.

Parasternal short axis view of the tricuspid valve ${ }^{7}$-From the parasternal short axis view of the left ventricle at mitral valve level, medial and inferior tilting of the transducer results in a minor axis view of the right ventricular inflow tract immediately below the tricuspid valve leaflets (Fig. 2). The measurement of this region (RVIT ${ }_{2}$ ) was defined as the maximum perpendicular distance from the right side of the mid-interventricular septum to the right ventricular free wall.

Apical four chamber view ${ }^{9}$-From an apical four chamber view the ultrasound beam was orientated to obtain the maximum dimensions of the right ventric- 

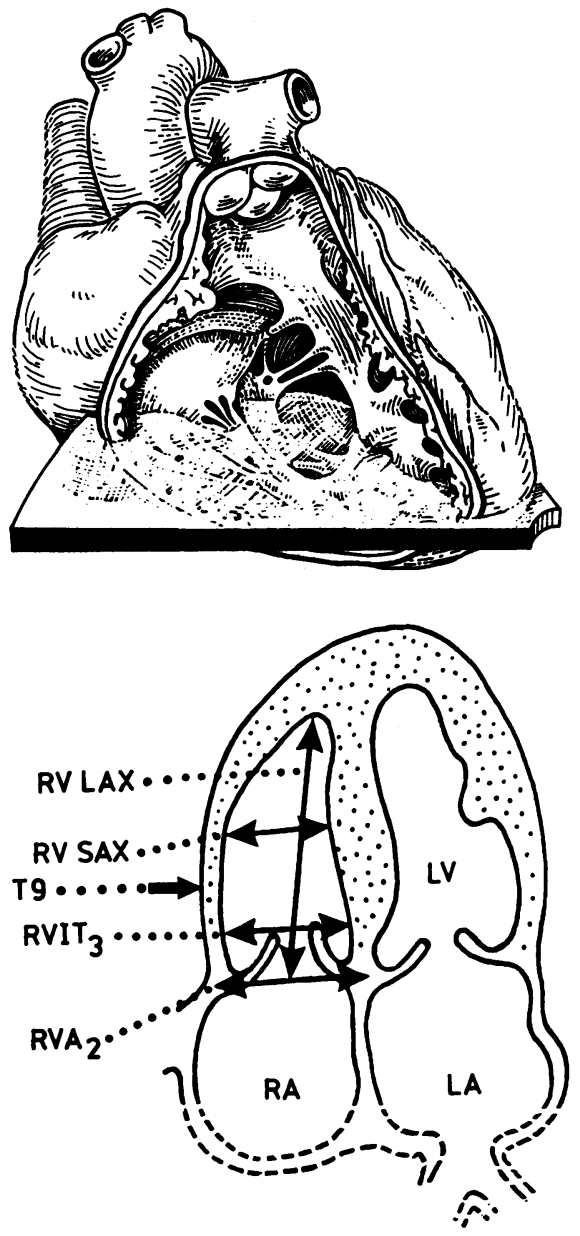

Fig. 3 Apical four chamber view. See text for measurements and abbreviations.

ular chamber (Fig. 3). Measurements were made of the tricuspid valve annulus (RVA $)$, defined as the point of attachment of the septal and posterior leaflets to the atrioventricular junction, and of the minor axis of the right ventricular inflow tract $\left(\mathrm{RVIT}_{3}\right)$ taken within one third of the distance below the tricuspid valve annulus towards the right ventricular apex.

Subcostal four chamber view-With both atria and ventricles viewed in a long axis projection (Fig. 4), the right ventricle was aligned to obtain the maximum dimensions of the minor axis of the right ventricular inflow tract (RVIT 4 ), measured just below the tricuspid valve within one third of the distance towards the cardiac apex.
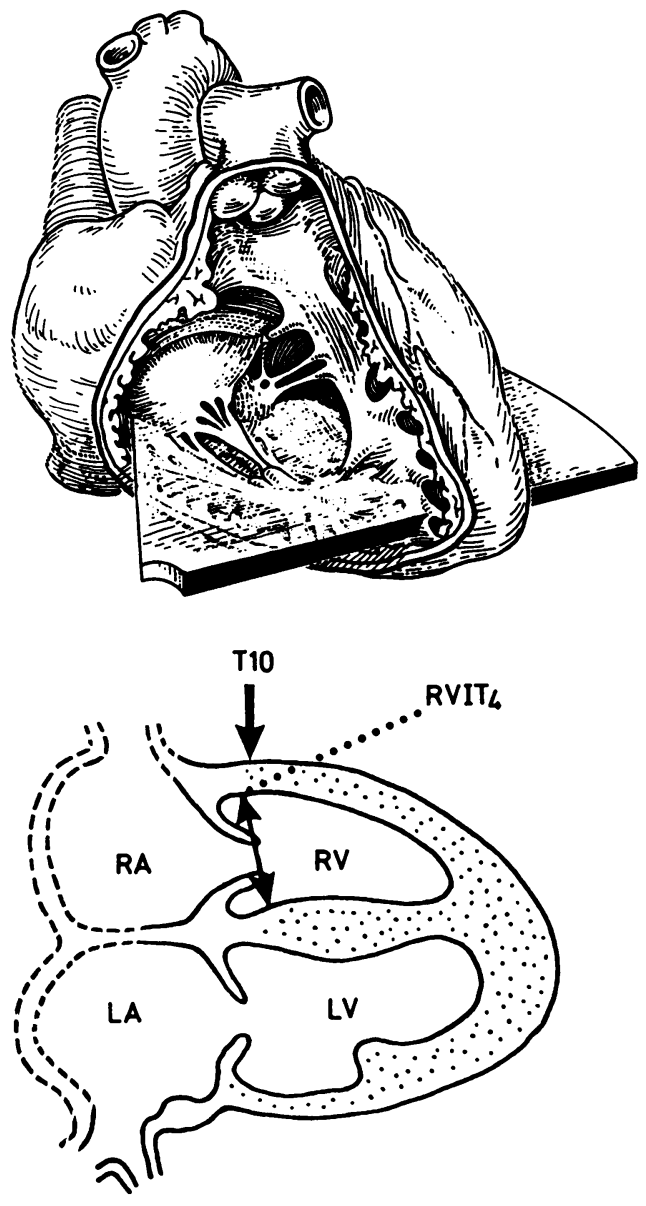

Fig. 4 Subcostal four chamber view. See text for measurements and abbreviations.

Right ventricular outflow tract

Measurements of this region were taken from three separate transducer locations.

Parasternal view of the left heart-We used $M$ mode echocardiography to measure the right ventricle anteriorly to the echoes which represent the intraventricular septum. ${ }^{3}$ The parasternal long axis view of the left ventricle obtained by cross sectional echocardiography (Fig. 5) identifies this Mmode dimension as the proximal region of the right ventricular outflow tract $\left(\mathrm{RVOT}_{1}\right)$. Measurements were made from the right side of the interventricular septum to the anterior right ventricular free wall.

Right ventricular outflow tract view ${ }^{6}$-From the parasternal long axis view of the left heart the true 

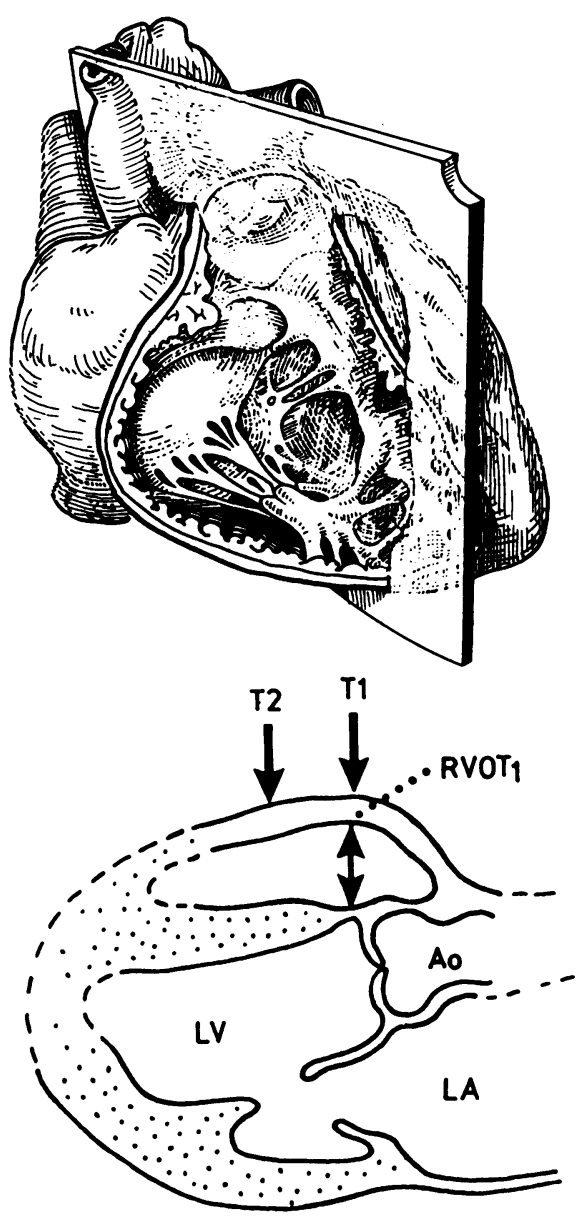

Fig. 5 Parasternal view of the left heart (with proximal right ventricular outflow tract). See text for measurements and abbreviations.

long axis of the right ventricular outflow tract was visualised by leftward and superior angulation of the transducer (Fig. 6). With this manoeuvre the maximum dimensions of the pulmonary annulus and proximal main pulmonary artery were kept in the same imaging plane. Measurements were taken of the right ventricular outflow tract from the region approximately $2 \mathrm{~cm}$ below the annulus where the right ventricular anterior wall myocardium was discernible $\left(\mathrm{RVOT}_{2}\right)$ and from just beneath the pulmonary valve annulus $\left(\mathrm{RVOT}_{3}\right)$. This region of the right heart may also be viewed from the subcostal transducer position and has been well described in infants and children. ${ }^{10}$ In the adults of our study, however, the location of the outflow tract in the far
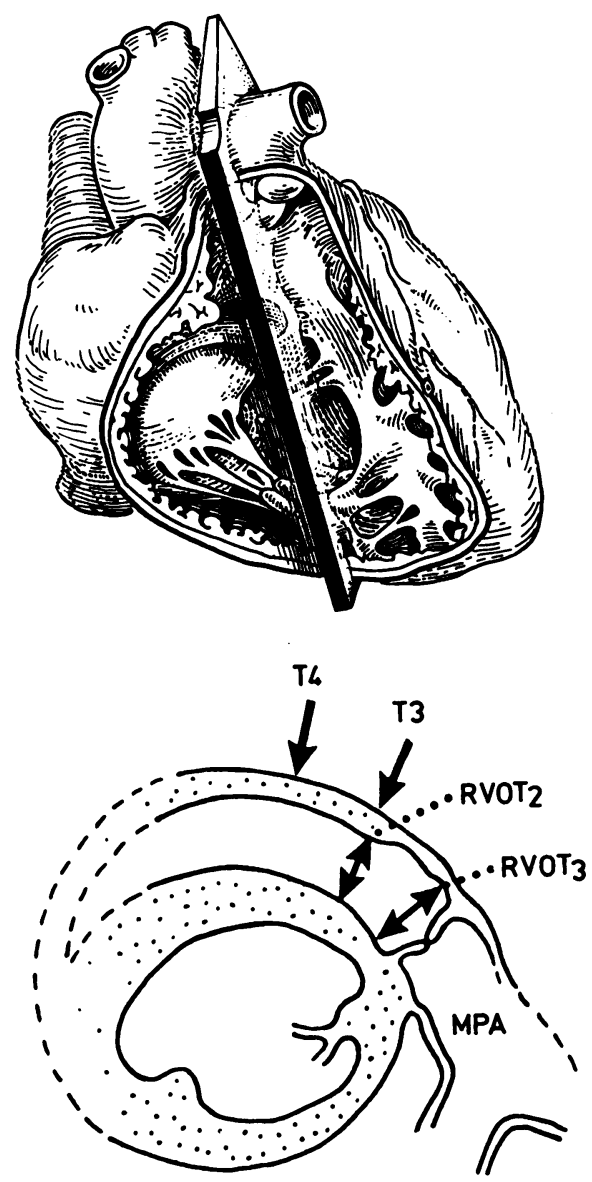

Fig. 6 Right ventricular outflow tract view. See text for measurements and abbreviations.

field of this view, while allowing for gross morphological description of the area, provided too poor an edge discrimination for reliable measurement.

Parasternal short axis view of the aortic root-The right ventricular outflow tract from this view was measured anteriorly to the aortic root as the maximum dimension between the anterior aortic wall and the right ventricular free wall endocardium $\left(\right.$ RVOT $_{4}$ ) (Fig. 7).

Right ventricular body

One transducer location only was used for measurement of this region of the ventricle.

Apical four chamber view-The middle third of the right ventricle was identified as lying below the 

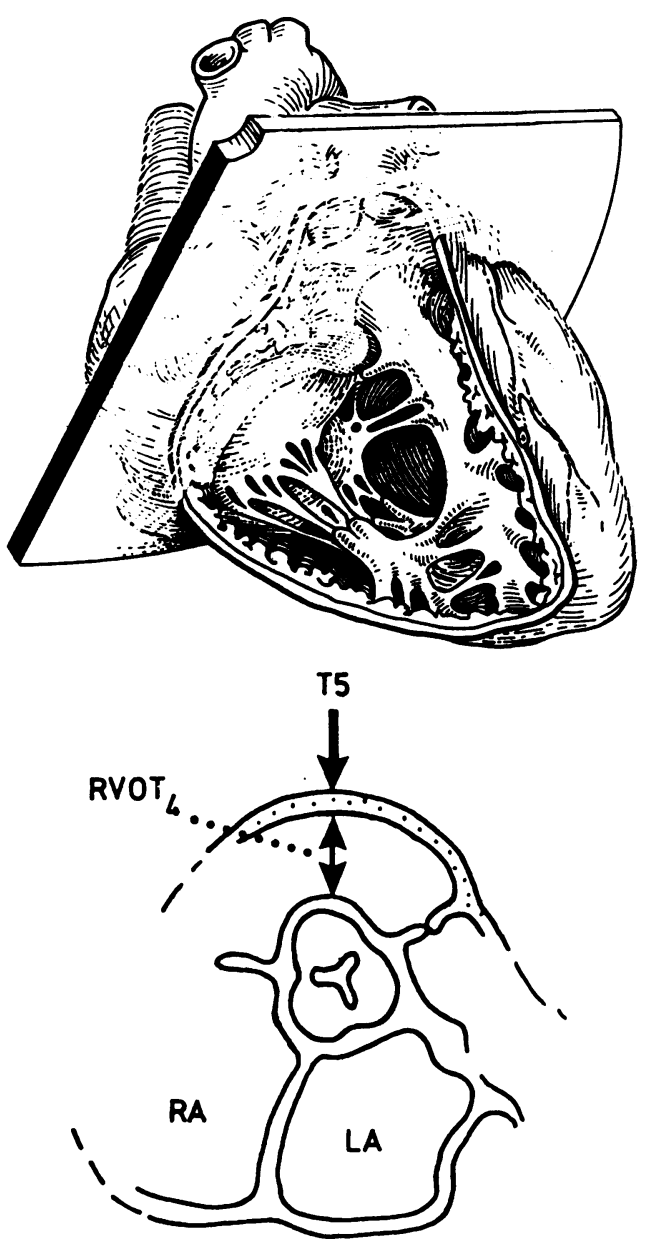

Fig. 7 Parasternal short axis view of the aortic root. See text for measurements and abbreviations.

inflow tract region (Fig. 3). A measurement of the maximum dimension of this portion of the chamber, defined as the body, was taken (RV SAX). From this view both the lateral free wall of the ventricle and the right side of the interventricular septum lie parallel with the ultrasound beam; thus the endocardial echo, particularly that from the lateral wall, may on occasion spread over 3-5 mm. In these cases the midpoint of this signal was taken as the point from which to measure the distance between right ventricular septal surface and free wall. The major axis of the right ventricle (RV LAX) was also measured from this view and was defined as the distance between the right ventricular apex to the mid-point of the tricuspid valve annulus.
RIGHT VENTRICULAR WALL THICRNESS

A total of ten different regions of right ventricular free wall were measured from the four transducer positions and orientations described above (Figs. 1 to 7).

Measurements T1-5 were taken from the views which imaged the right ventricular outflow tract (Figs. 5-7). Measurements T6-10 were of the free wall of the right ventricular inflow tract and body (Figs. 1, 3 and 4). Measurements T6-8 were taken from the parasternal right ventricular inflow tract view (Fig. 1), T6 and T7 were measurements of the anterior wall of this region of the right ventricle, and T8 was a measurement of the posteromedial wall. The thickness of the lateral wall of the right ventricle (T9) was measured from the apical four chamber view (Fig. 3). T10 was a measurement of the diaphragmatic wall of the right ventricle taken from the subcostal four chamber view (Fig. 4).

\section{ECHOCARDIOGRAPHIC ANALYSIS}

Video recordings of optimal $M$ mode and cross sectional echocardiographic images from each part of the examination sequence, together with standard lead II of an electrocardiogram, were stored on videotape for subsequent analysis.

Measurements from $M$ mode or cross sectional echocardiographic images were performed by a commercially available offline analysis system (Microsonics, Indianapolis, Indiana, USA). This uses a joystick operated cursor which minimises the measurement errors due to parallax. Measurements were taken from the $M$ mode recording when this coincided with the major or minor axis of the right ventricle; when it did not measurements were taken directly from the cross sectional image in stop-frame format. All measurements were performed at end diastole, which was defined as the frame closest to the onset of the $\mathbf{R}$ wave of the electrocardiogram. Right ventricular cavity dimension and right ventricular wall thickness were measured from the leading edge to the leading edge of the endocardial or epicardial signals. Three values for each dimension or thickness were made from three consecutive cardiac cycles. The measurements were averaged and the resulting value was used in the statistical analysis.

\section{STATISTICAL ANALYSIS}

Absolute measurements and those corrected for body surface area were expressed as mean (2 SD). The coefficient of variation was calculated for each dimension and wall thickness as:

$$
\frac{\text { Standard deviation }}{\text { Mean }} \times 100 \%
$$


Table 2 Right ventricular chamber size: absolute measurements from 41 normal subjects at end diastole

\begin{tabular}{|c|c|c|c|c|c|}
\hline & No (41) & Mean $(\mathrm{cm})$ & $2 S D$ & Range & $\begin{array}{l}\text { Coefficient of variation } \\
\text { (within measurements) (\%) }\end{array}$ \\
\hline $\begin{array}{l}\text { RVIT }_{1} \\
\text { RVIT }_{2} \\
\text { RVIT }_{3} \\
\text { RVIT }_{4}\end{array}$ & $\begin{array}{l}40 \\
29 \\
38 \\
29\end{array}$ & $\begin{array}{l}4.5 \\
3.0 \\
2.4 \\
5 \cdot 1\end{array}$ & $\begin{array}{l}0.5 \\
0.3 \\
0.4 \\
0.5\end{array}$ & $\begin{array}{l}3 \cdot 7-5 \cdot 4 \\
2 \cdot 4-3 \cdot 9 \\
1.5-3.0 \\
4 \cdot 0-7 \cdot 0\end{array}$ & $\begin{array}{l}10.6 \\
12 \cdot 2 \\
16 \cdot 1 \\
11 \cdot 2\end{array}$ \\
\hline $\begin{array}{l}\text { RVOT }_{1} \\
\text { RVOT }_{2} \\
\text { RVOT }_{3} \\
\text { RVOT }_{4}\end{array}$ & $\begin{array}{l}41 \\
41 \\
41 \\
41\end{array}$ & $\begin{array}{l}2 \cdot 2 \\
2 \cdot 3 \\
2 \cdot 0 \\
2 \cdot 7\end{array}$ & $\begin{array}{l}0.3 \\
0 \cdot 3 \\
0 \cdot 3 \\
0 \cdot 2\end{array}$ & $\begin{array}{l}1.8-3.0 \\
1.8-2.9 \\
1.4-2.6 \\
2.0-3.2\end{array}$ & $\begin{array}{l}13.4 \\
13.0 \\
15.0 \\
10.1\end{array}$ \\
\hline $\begin{array}{l}\text { RV LAX } \\
\text { RV SAX }\end{array}$ & $\begin{array}{l}40 \\
40\end{array}$ & $\begin{array}{l}7.6 \\
3.0\end{array}$ & $\begin{array}{l}0.5 \\
0.3\end{array}$ & $\begin{array}{l}6 \cdot 9-8 \cdot 9 \\
2 \cdot 4-3 \cdot 7\end{array}$ & $\begin{array}{r}5.9 \\
10 \cdot 2\end{array}$ \\
\hline $\begin{array}{l}\text { RVA } \\
\text { RVA }_{2}\end{array}$ & $\begin{array}{l}41 \\
41\end{array}$ & $\begin{array}{l}3 \cdot 4 \\
2 \cdot 4\end{array}$ & $\begin{array}{l}0.3 \\
0.3\end{array}$ & $\begin{array}{l}2 \cdot 5-4 \cdot 0 \\
1 \cdot 6-3 \cdot 1\end{array}$ & $\begin{array}{r}9 \cdot 5 \\
14 \cdot 1\end{array}$ \\
\hline
\end{tabular}

Coefficient of variation (between measurements) mean (1 SD) 51 (12)\%, range 36-72\%.

Table 3 Right ventricular chamber size: measurements from 41 normal subjects at end diastole corrected for body surface area

\begin{tabular}{|c|c|c|c|c|c|}
\hline & No (41) & Mean (cm) & $2 S D$ & Range & $\begin{array}{l}\text { Coefficient of variation } \\
\text { (within measurements) (\%) }\end{array}$ \\
\hline $\begin{array}{l}\text { RVIT }_{1} \\
\text { RVIT }_{2} \\
\text { RVIT }_{3} \\
\text { RVIT }_{4}\end{array}$ & $\begin{array}{l}40 \\
29 \\
38 \\
29\end{array}$ & $\begin{array}{l}2.6 \\
1.7 \\
1.4 \\
2.9\end{array}$ & $\begin{array}{l}0.3 \\
0.2 \\
0.2 \\
0.4\end{array}$ & $\begin{array}{l}2.0-3.3 \\
1.4-2.0 \\
1.0-1.8 \\
2.3-3.6\end{array}$ & $\begin{array}{l}11.8 \\
10.8 \\
16.1 \\
12.3\end{array}$ \\
\hline $\begin{array}{l}\text { RVOT }_{1} \\
\text { RVOT }_{2} \\
\text { RVOT }_{3} \\
\text { RVOT }_{4}\end{array}$ & $\begin{array}{l}41 \\
41 \\
41 \\
41\end{array}$ & $\begin{array}{l}1.3 \\
1.3 \\
1.1 \\
1.6\end{array}$ & $\begin{array}{l}0.2 \\
0.3 \\
0.1 \\
0.2\end{array}$ & $\begin{array}{l}1.0-1.7 \\
1.0-2.9 \\
0.9-1.4 \\
1.2-2.0\end{array}$ & $\begin{array}{l}12.6 \\
22.5 \\
12.4 \\
12.7\end{array}$ \\
\hline $\begin{array}{l}\text { RV LAX } \\
\text { RV SAX }\end{array}$ & $\begin{array}{l}40 \\
40\end{array}$ & $\begin{array}{l}4.4 \\
1.8\end{array}$ & $\begin{array}{l}0.4 \\
0.2\end{array}$ & $\begin{array}{l}3 \cdot 6-5 \cdot 4 \\
1 \cdot 4-2 \cdot 2\end{array}$ & $\begin{array}{r}9 \cdot 1 \\
12 \cdot 7\end{array}$ \\
\hline $\begin{array}{l}\mathbf{R V A}_{1} \\
\mathbf{R V A}_{2}\end{array}$ & $\begin{array}{l}41 \\
41\end{array}$ & $\begin{array}{l}2.0 \\
1.5\end{array}$ & $\begin{array}{l}0.2 \\
0.2\end{array}$ & $\begin{array}{l}1 \cdot 6-2 \cdot 4 \\
1 \cdot 1-1 \cdot 8\end{array}$ & $\begin{array}{l}10 \cdot 2 \\
14 \cdot 3\end{array}$ \\
\hline
\end{tabular}

Coefficient of variation (between measurements) mean (1 SD) 51 (12)\%, range $37-72 \%$.

This value expresses the spread of values about the mean. The coefficient of variation may be used to measure regional asymmetry of cavity size or wall thickness when calculated for the different measurements within individuals. When calculated for the same measurement between individuals, the coefficient of variation shows the normal variability of the measurement in a population. If it is assumed that, like other cardiac dimensions, this variability is relatively small, then the coefficient of variation may also be considered as a function of the ease of standardisation of that view from which the measurement was made-that is the ease of obtaining the same "on axis" view for different patients.

Intraobserver variability was tested by a second analysis of 10 randomly selected studies. Measurements were performed blindly by the first observer at least 14 days after the first analysis. Inter- observer variability was tested by a second observer for the same randomly selected studies. Interobserver and intraobserver variability were expressed both as the range of absolute difference and the percentage difference between the two measurements.

\section{Results}

\section{RIGHT VENTRICULAR CHAMBER SIZE}

Tables 2 and 3 show the results for absolute measurements of the right ventricular cavity and those corrected for body surface area. The frequency with which each measurement was made is shown. Table 4 shows the results for interobserver and intraobserver variability for the absolute measurement.

Of the right ventricular inflow tract views, $\mathrm{RVIT}_{2}$, from the parasternal short axis view, and 
Table 4 Inter- and intraobserver variability of the absolute measurements of right ventricular chamber size

\begin{tabular}{|c|c|c|c|c|c|c|c|c|}
\hline & \multicolumn{4}{|c|}{ Interobserver } & \multicolumn{4}{|c|}{ Intraobserver } \\
\hline & \multicolumn{2}{|c|}{ Absolute difference } & \multicolumn{2}{|c|}{$\%$ of difference } & \multicolumn{2}{|c|}{ Absolute difference } & \multicolumn{2}{|c|}{$\%$ of difference } \\
\hline & $\begin{array}{l}\text { Mean } \\
(\mathrm{cm})\end{array}$ & $2 S D$ & Mean & $2 S D$ & $\begin{array}{l}\text { Mean } \\
(\mathrm{cm})\end{array}$ & $2 S D$ & Mean & $2 S D$ \\
\hline $\begin{array}{l}\text { RVIT }_{1} \\
\text { RVIT }_{2} \\
\text { RVIT }_{3} \\
\text { RVIT }_{4}\end{array}$ & $\begin{array}{l}0.04 \\
1.0 \\
0.2 \\
0.1\end{array}$ & $\begin{array}{l}0.4 \\
0.4 \\
0.3 \\
0.7\end{array}$ & $\begin{array}{c}1.5 \\
54 \\
5 \cdot 7 \\
0.8\end{array}$ & $\begin{array}{l}0.1 \\
0.4 \\
0.1 \\
0.1\end{array}$ & $\begin{array}{l}0.03 \\
0.08 \\
0.07 \\
0.2\end{array}$ & $\begin{array}{l}0.5 \\
0.4 \\
0.3 \\
0.7\end{array}$ & $\begin{array}{l}0.03 \\
2 \cdot 4 \\
2 \cdot 8 \\
4 \cdot 5\end{array}$ & $\begin{array}{l}0.1 \\
0.1 \\
0.1 \\
0.1\end{array}$ \\
\hline $\begin{array}{l}\text { RVOT }_{1} \\
\text { RVOT }_{2} \\
\text { RVOT }_{3} \\
\text { RVOT }_{4}\end{array}$ & $\begin{array}{l}0.2 \\
0.3 \\
0.2 \\
0.2\end{array}$ & $\begin{array}{l}0.3 \\
0.3 \\
0.3 \\
0.4\end{array}$ & $\begin{array}{c}5 \cdot 7 \\
14 \\
7 \cdot 1 \\
12\end{array}$ & $\begin{array}{l}0.1 \\
0 \cdot 1 \\
0 \cdot 1 \\
0.2\end{array}$ & $\begin{array}{l}0.1 \\
0.3 \\
0.09 \\
0.05\end{array}$ & $\begin{array}{l}0.2 \\
0 \cdot 2 \\
0.3 \\
0 \cdot 2\end{array}$ & $\begin{array}{c}6 \cdot 1 \\
13 \\
5 \cdot 2 \\
1 \cdot 4\end{array}$ & $\begin{array}{l}0.1 \\
0.1 \\
0.1 \\
0.1\end{array}$ \\
\hline $\begin{array}{l}\text { RV LAX } \\
\text { RV SAX }\end{array}$ & $\begin{array}{l}0.3 \\
0.2\end{array}$ & $\begin{array}{l}0.6 \\
0.7\end{array}$ & $10^{3 \cdot 8}$ & $\begin{array}{l}0.1 \\
0.3\end{array}$ & $\begin{array}{l}0.3 \\
0.04\end{array}$ & $\begin{array}{l}0.5 \\
0.4\end{array}$ & $\begin{array}{l}3.8 \\
1.1\end{array}$ & $\begin{array}{l}0.1 \\
0.2\end{array}$ \\
\hline $\begin{array}{l}\text { RVA }_{1} \\
\text { RVA }_{2}\end{array}$ & $\begin{array}{l}0.06 \\
0.2\end{array}$ & $\begin{array}{l}0.5 \\
0.3\end{array}$ & $\begin{array}{l}0.6 \\
6.0\end{array}$ & $\begin{array}{l}0.1 \\
0.1\end{array}$ & $\begin{array}{l}0.2 \\
0.1\end{array}$ & $\begin{array}{l}0.2 \\
0.3\end{array}$ & $\begin{array}{l}5.9 \\
3.0\end{array}$ & $\begin{array}{l}0.1 \\
0.1\end{array}$ \\
\hline
\end{tabular}

Table 5 Right ventricular wall thickness: end diastolic measurements from 41 normal subjects

\begin{tabular}{|c|c|c|c|c|c|c|c|c|}
\hline \multirow{2}{*}{$\begin{array}{l}R V \text { wall } \\
\text { region }\end{array}$} & \multicolumn{4}{|c|}{ Absolute values $(\mathrm{cm})$} & \multicolumn{4}{|c|}{ Corrected for $B S A\left(m^{2}\right)$} \\
\hline & Mean & $2 S D$ & Range & $\begin{array}{l}\text { Coefficient of } \\
\text { variation (vithin } \\
\text { measurements) (\%) }\end{array}$ & Mean & $2 S D$ & Range & $\begin{array}{l}\text { Coefficient of } \\
\text { variation (within } \\
\text { measurements) }(\%)\end{array}$ \\
\hline $\begin{array}{l}\text { T1 } \\
\text { T2 } \\
\text { T3 } \\
\text { T4 } \\
\text { T5 } \\
\text { T6 } \\
\text { T7 } \\
\text { T8 } \\
\text { T9 } \\
\text { T10 }\end{array}$ & $\begin{array}{l}0.3 \\
0.3 \\
0.3 \\
0.4 \\
0.3 \\
0.3 \\
0.4 \\
0.4 \\
0.4 \\
0.4\end{array}$ & $\begin{array}{l}0.07 \\
0.07 \\
0.05 \\
0.07 \\
0.08 \\
0.06 \\
0.07 \\
1.0 \\
0.07 \\
1.0\end{array}$ & $\begin{array}{l}0.2-0.5 \\
0.2-0.5 \\
0.3-0.5 \\
0.2-0.5 \\
0.2-0.5 \\
0.2-0.5 \\
0.3-0.5 \\
0.3-0.6 \\
0.3-0.6 \\
0.3-0.7\end{array}$ & $\begin{array}{l}20.7 \\
21.5 \\
15.9 \\
18.6 \\
21.8 \\
17.7 \\
20.2 \\
25.5 \\
16.7 \\
24.5\end{array}$ & $\begin{array}{l}0.2 \\
0.2 \\
0.2 \\
0 \cdot 2 \\
0 \cdot 2 \\
0 \cdot 2 \\
0 \cdot 2 \\
0 \cdot 2 \\
0.2 \\
0.2\end{array}$ & $\begin{array}{l}0.04 \\
0.05 \\
0.04 \\
0.04 \\
0.05 \\
0.04 \\
0.05 \\
0.06 \\
0.05 \\
0.06\end{array}$ & $\begin{array}{l}0.1-0.3 \\
0.1-0.3 \\
0.1-0.3 \\
0.1-0.3 \\
0.1-0.3 \\
0.1-0.3 \\
0.1-0.3 \\
0.1-0.4 \\
0.1-0.3 \\
0.1-0.4\end{array}$ & $\begin{array}{l}22 \cdot 4 \\
23 \cdot 6 \\
20 \cdot 1 \\
22 \cdot 0 \\
25 \cdot 8 \\
21 \cdot 1 \\
24 \cdot 1 \\
26 \cdot 6 \\
21 \cdot 1 \\
27 \cdot 4\end{array}$ \\
\hline
\end{tabular}

Coefficient of variation (between measurements) mean (1 SD) 17 (14\%), range 3-31\% for absolute values; 17 (14)\%, range 8-35\% for BSA corrected values. BSA, body surface area.

Table 6 Inter-and intraobserver variability of the absolute measurements of right ventricular wall thickness

\begin{tabular}{|c|c|c|c|c|c|c|c|c|}
\hline \multirow{3}{*}{$\begin{array}{l}R V \text { wall } \\
\text { region }\end{array}$} & \multicolumn{4}{|c|}{ Interobserver } & \multicolumn{4}{|c|}{ Intraobserver } \\
\hline & \multicolumn{2}{|c|}{ Absolute difference } & \multicolumn{2}{|c|}{$\%$ of difference } & \multicolumn{2}{|c|}{ Absolute difference } & \multicolumn{2}{|c|}{$\%$ of difference } \\
\hline & $\begin{array}{l}\text { Mean } \\
(\mathrm{cm})\end{array}$ & $2 S D$ & Mean & $2 S D$ & $\begin{array}{l}\text { Mean } \\
(\mathrm{cm})\end{array}$ & $2 S D$ & Mean & $2 S D$ \\
\hline $\begin{array}{l}\text { T1 } \\
\text { T2 } \\
\text { T3 } \\
\text { T4 } \\
\text { T5 } \\
\text { T6 } \\
\text { T7 } \\
\text { T8 } \\
\text { T9 } \\
\text { T10 }\end{array}$ & $\begin{array}{l}0.04 \\
0.01 \\
0.05 \\
0.02 \\
0.0 \\
0.02 \\
0.03 \\
0.06 \\
0.02 \\
0.09\end{array}$ & $\begin{array}{l}0.2 \\
0.12 \\
0.18 \\
0.18 \\
0.2 \\
0.2 \\
0.18 \\
0.2 \\
0.4 \\
0.18\end{array}$ & $\begin{array}{r}18 \\
6 \\
23 \\
11 \\
11 \\
15 \\
4 \\
9 \\
6 \\
19\end{array}$ & $\begin{array}{r}74 \\
21 \\
70 \\
52 \\
100 \\
41 \\
56 \\
64 \\
96 \\
36\end{array}$ & $\begin{array}{l}0.1 \\
0.02 \\
0.07 \\
0.05 \\
0.05 \\
0.04 \\
0.0 \\
0.01 \\
0.07 \\
0.04\end{array}$ & $\begin{array}{l}0.14 \\
0.16 \\
0.1 \\
0.1 \\
0.2 \\
0.14 \\
0.1 \\
0.2 \\
0.2 \\
0.1\end{array}$ & $\begin{array}{r}26 \\
4 \\
19 \\
13 \\
12 \\
9 \\
1 \\
8 \\
14 \\
13\end{array}$ & $\begin{array}{l}32 \\
48 \\
28 \\
26 \\
56 \\
38 \\
32 \\
58 \\
74 \\
32\end{array}$ \\
\hline
\end{tabular}



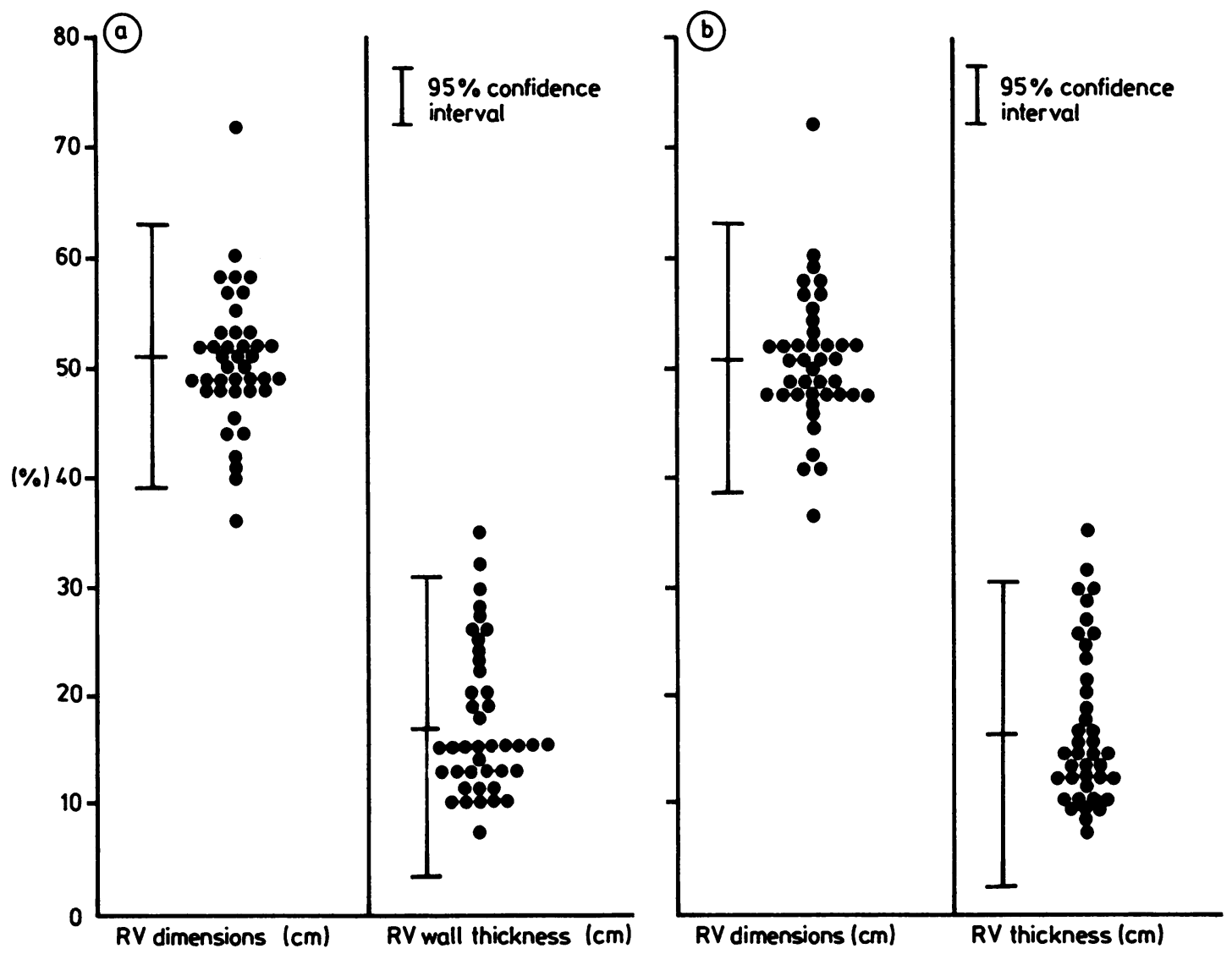

Fig. 8 Coefficient of variation for measurements corrected for body surface area (a) and absolute measurements (b) of right ventricular cavity size and right ventricular free wall thickness.

RVIT $_{4}$, from the subcostal view, were least often obtained $(29(70 \%)$ of 41 studies for each view). The absolute measurement of inflow tract with the least variability, as measured by a coefficient of variation of $10.6 \%$, was RVIT $_{1}$; differences between measurements of this value were $<5 \%$. The results for RVIT $_{1}$, RVIT $_{3}$, and RVIT 4 showed a high degree of reproducibility (Table 4 ) with an interobserver and intraobserver variability of $<10 \%$. The interobserver variability for measurement of RVIT $_{2}$ was poor, however, at $54 \%$.

Measurements of the right ventricular outflow tract were obtained in all patients and fell within a narrow range. The spread of values indicated by a coefficient of variation for absolute values of $\leqslant 15 \%$ was also small. The results for all four measurements mostly showed acceptable reproducibility. For RVOT $_{2}$, however, interobserver and intraobserver variability were $14 \%$ and $13 \%$ respectively. The interobserver variability for $\mathrm{RVOT}_{4}$ was $12 \%$. Both measurements of the right ventricular body showed a good coefficient of variation (in the region of $10 \%$ ) and interobserver and intraobserver variabilities were low.

The measurements of tricuspid annulus from orthogonal planes showed an acceptable spread of values with coefficient of variations of $<15 \%$ and good interobserver and intraobserver variability.

The coefficient of variation measured within individuals for different measurements of cavity size (Fig. 8) showed a high degree of variability (51 $(12) \%$, range $36-72 \%$ ), as was expected given the markedly asymmetrical shape of the chamber.

\section{RIGHT VENTRICULAR WALL THICKNESS}

Tables 5 and 6 show the results for right ventricular wall thickness in the ten measured regions of right ventricular free wall. Although earlier echo- 
cardiographic studies have suggested that normal wall thickness for the right ventricle is $<0.4 \mathrm{~cm}$ (range $0.2-0.4 \mathrm{~cm}$ ), our results indicate that right ventricular wall thickness may show a regional variation of between $0.2 \mathrm{~cm}$ and $0.7 \mathrm{~cm}$. Values of the coefficient of variation of $>25 \%$ for different measurements within subjects suggest that the right ventricular free wall is asymmetric in some normal individuals (Fig. 8). The values for the coefficient of variation for the same measurement between subjects of mostly $>20 \%$ were less satisfactory than for right ventricular cavity dimensions, suggesting that these measurements will be less easily standardised. Furthermore, the reproducibility of some of these measurements was poor, with interobserver and intraobserver variations of up to $23 \%$ and $26 \%$ respectively.

These results for wall thickness, however, represent differences of 0.1 or $0.2 \mathrm{~cm}$, which fall near the resolution limits of most echocardiographic systems. Also although efforts were made to exclude trabecular echoes from the assessment of wall thickness, failure to have done so may easily account for the apparent limited reproducibility of some of these measurements.

\section{Discussion}

Disorders of right ventricular function may result from many disease states that directly affect heart muscle or which impose abnormal loading conditions upon the right sided chambers. Recently there has been considerable interest in the investigation of such abnormalities by various non-invasive techniques. $^{45}$ Echocardiography is one which has become increasingly used in the measurement of cardiac structure and function as methodology and image quality have advanced. Our study was prompted by the need for a standardised approach to the echocardiographic examination of the right ventricle $^{5}$ and to obtain a range of normal values for internal cavity dimension and right ventricular free wall thickness from the several views that we used.

We believe that an evaluation of the right ventricle should be part of every routine echocardiographic study. We hold this view because, firstly, many disorders of the right ventricle may not result in obvious clinical signs or may be overshadowed by left sided abnormalities. Secondly, the right ventricular specific views may be difficult to obtain, and the experience gained by the echocardiographer in attempting these views in every study should provide the necessary expertise when the clinical indication calls for a specific examination of the right sided chambers.
NORMAL RIGHT VENTRICULAR END DIASTOLIC CHAMBER DIMENSIONS

Because the inflow tract, ventricular body, and outflow tract are three distinct regions of the right ventricle that are orientated in different axes, measurements of each region should be obtained from separate views.

The measurements of the right ventricular inflow tract that we have used mostly show little variation around the mean, as shown by coefficients of variations in the order of $15 \% . \mathrm{RVIT}_{2}$, the measurement from the parasternal short axis of the left ventricle with tilt towards the tricuspid valve, showed an interobserver variability of $54 \%$, suggesting that it may be difficult to standardise. Furthermore, it was only available in a limited number of patients $(70 \%)$. Similarly, RVIT $_{4}$, the measurement from the subcostal view, was available in $70 \%$ of patients and it showed a low coefficient of variation with good reproducibility. Of all the right ventricular inflow tract measurements, the most easily obtained and reproducible measurements of the right ventricular inflow tract came from the two views in orthogonal planes-RVIT ${ }_{1}$ from the specific parasternal right ventricular inflow tract view and RVIT $_{3}$ from the apical four chamber view.

Most measurements of the right ventricular outflow tract showed satisfactory degrees of reproducibility and little variation. The right ventricular outflow tract measurement RVOT $_{1}$, as taken by $M$ mode and cross sectional echocardiography from a parasternal long axis view of the left heart, is neither true outflow tract nor true right ventricular body. Because it is desirable to relate the results of $M$ mode studies to those obtained with cross sectional echocardiography, however, this measurement was included in our protocol. Indeed, RVOT $_{1}$ showed a high degree of reproducibility and also had a low coefficient of variation. The measurement of this same region from the parasternal short axis view of the aortic root $\left(\mathrm{RVOT}_{4}\right)$ was larger and was less reproducible, with an interobserver variation of $12 \%$. These minor discrepancies may be explained by the differences in obtaining images from short axis and long axis projections. A short axis plane is more likely to pass obliquely through this region and thus provide a larger measurement because there are no satisfactory internal landmarks upon which to orientate the image with precision. By keeping the interventricular septum and anterior aortic wall parallel to the chest wall in the parasternal long axis view of the left heart, better "on axis" measurements may be made. Thus, RVOT ${ }_{1}$ is a better measure of outflow tract than RVOT $_{4}$. The specific right ventricular outflow tract view from which $\mathrm{RVOT}_{2}$ and $\mathrm{RVOT}_{3}$ were derived was obtained in all patients in 
the study group. RVOT $_{2}$, however, had less satisfactory interobserver and intraobserver variability, although absolute differences were no more than $0.3 \mathrm{~cm}$. RVOT 3 , the measurement of the outflow tract immediately below the pulmonary valve annulus, was highly reproducible and showed little variation in normal subjects.

Difficulties were experienced in obtaining precise on axis views for the right ventricular body from projections other than the apical four chamber view. Even from this view it was not always clear where the minor axis of the right ventricular body should be measured. Schnittger et $a l^{11}$ have followed other groups ${ }^{7}$ by taking this measurement at a fixed distance in the chamber-that is one third of the way down the major axis from the atrioventricular ring. In our experience, however, this fixed distance measurement does not always coincide with the maximum short axis diameter.

We measured the maximum short axis diameter of the body of the ventricle taken below the inflow measurement but within the middle third of this imaged cavity. Nuances of apex identification and chamber shape are taken into account by this approach although it is clear that precise identification of endocardial signal may not always be possible from this view. Our measurements of the minor axis, however, showed little variation and had satisfactory reproducibility. Similarly, the long axis measurement of the right ventricular body was satisfactory in most cases.

NORMAL RIGHT VENTRICULAR END DIASTOLIC WALL THICKNESS

In our group of normal subjects, the mean right ventricular free wall thickness was not $>0.4 \mathrm{~cm}$. Individual values, however, ranged up to $0.7 \mathrm{~cm}$.

The mean coefficient of variation of $17 \%$ in individual measurements between subjects showed that the right ventricular free wall is fairly symmetrical. Several individuals, however, had values $>25 \%$ and thus a degree of free wall asymmetry should be expected in some normal subjects. The variations in free wall thickness are seen particularly in the lateral and diaphragmatic regions. In performing these measurements, we have attempted to exclude dense trabecular patterns by careful review of the study in real time format. During replay the trabeculae should easily be distinguished from true right ventricular free wall; however, it is possible that differences in trabecular patterns could explain the exaggerated wall thickness measurements in some cases. Accurate measurements of abnormally increased right ventricular wall thickness are difficult to obtain in regions other than the outflow tract where, despite absence of heavy trabeculation, nor- mal wall thickness of $0.4-0.5 \mathrm{~cm}$ are described. ${ }^{12} \mathrm{~A}$ further explanation for the regional variation in wall thickness measurements may be limited reproducibility ( $\leqslant 23 \%$ ); however, measurements below $0.5 \mathrm{~cm}$ in echocardiography are of small absolute differences which may be at the resolution limit of most ultrasound systems. We consider that values of $\geqslant 0.7 \mathrm{~cm}$ for right ventricular wall thickness (or $0.4 \mathrm{~cm} / \mathrm{m}^{2}$ ) should certainly be regarded as abnormal; but if they are isolated and obtained from the lateral or diaphragmatic walls they should be interpreted with caution.

Our results for normal right ventricular cavity dimensions at end diastole and for normal values of right ventricular diastolic wall thickness do not vary greatly from those measured by other groups. ${ }^{13-15}$ Our observations are taken from 41 subjects, however, the largest normal population studied to date and include a specific measurement of the right ventricular inflow tract (RVIT 1 ) and a detailed measurement of right ventricular wall thickness not previously described. We have also performed a more structured analysis of the right ventricle than the single plane orientation reported in the recent study by Schnittger $e t a l^{11}$ or by others in the determination of right ventricular volumes ${ }^{14-16}$ or ejection fractions. ${ }^{1718}$ From approximately similar projections our values for RVIT $_{1}$ resemble those that were measured by Bommer et $a^{13}$ and differ in only minor degrees from the results of Watanabe et al. ${ }^{15}$ These groups and others, ${ }^{18}$ however, have used as an equivalent to our specific right ventricular inflow tract view an orientation with the transducer positioned at the cardiac apex. Weyman has obtained this projection from the left parasternal edge, but has suggested that measurements of the inflow tract derived from this position may be difficult to standardise. ${ }^{14}$ Although we agree in part with this opinion, we believe that the measurements of this inflow tract plane from the cardiac apex often contain outflow tract as illustrated by Panidis $e a^{18}$ and so may be equally difficult to standardise. We were successful in imaging the long axis of the inflow tract of the right ventricle, including the tricuspid valve annulus and excluding outflow tract, from a transducer location approximately midway between the parasternal and apical positions. This measurement has a low coefficient of variation and was reproducible. Thus minor differences between our RVIT $_{1}$ measurements and those of others ${ }^{15}$ can be explained by our having excluded the proximal outflow tract from this view by careful positioning of the transducer between the parasternal and apical locations.

Unlike Starling et al ${ }^{17}$ we did not achieve success using subcostal views of the right ventricle as advo- 
cated by Tajik et al. ${ }^{6}$ These views are undoubtedly useful in children and in patients with severe chronic airways disease. The latter group invariably have a low diaphragm, and so the heart is closer to the transducer when it is in a subcostal location and image quality is enhanced. Although these views are deemed to be suitable for gross evaluation of right ventricular chamber anatomy, our experience in a normal adult population did not allow for more than one measurement of the cavity, that of the inflow tract $\left(\mathrm{RVIT}_{4}\right)$, and one measurement of right ventricular wall (T10) to be obtained. These views may be more useful in elderly patients in whom echocardiographic study from the parasternal and apical transducer positions may be technically more difficult than in patients of the age group that we studied.

We have not attempted to extend our measurements to those of systolic function because of the limitations imposed by chamber shape on the extrapolation of end diastolic and end systolic dimensions to overall right ventricular systolic function. ${ }^{14}$ Although difficulties in finding the appropriate model upon which an algorithm for this calculation should be based contribute to the problems of evaluating overall right ventricular function, there must also be uncertainty, caused by the rotation of the heart throughout the cardiac cycle, that the dimension obtained from systole is in the same plane of the right ventricular cavity as from diastole.

These factors are less limiting in the derivation of an ejection fraction index for the left ventricle because this cavity, at least in its normal condition, is a symmetrical ellipsoid. The perversities of right ventricular geometry must, however, limit the reliability of similar calculations for right ventricular function. Furthermore, most of the functional activity of the right ventricle comes from the body of the chamber. As this is the most difficult region of the right ventricle to measure, the functional status of the right ventricle may be better evaluated by techniques, such as radionuclide imaging methods, which despite their limitations are independent of geometric assumptions; that is until a satisfactory echocardiographic model is developed and the regional contribution to overall right ventricular function can be assessed.

\section{References}

1 Foale R, Stefanini L, Rickards A, Somerville J. Left and right ventricular morphology in complex congenital heart disease defined by two dimensional echocardiography. Am $\mathcal{f}$ Cardiol 1982; 49: 93-9.
2 Berger HJ, Matthay RA, Loke J, Marshall RC, Gottschalk A, Zaret BL. Assessment of cardiac performance with quantitative radionuclide angiography: right ventricular ejection fraction with reference to findings in chronic obstructive pulmonary disease. $\mathrm{Am}$ f Cardiol 1978; 41: 897-905.

3 Feigenbaum H. Echocardiography. 2nd ed. Philadelphia: Lea and Febiger, 1976: 255-66.

4 Manno BV, Iskandrian AS, Hakki AH. Right ventricular function: methodological and clinical considerations in non invasive scintigraphic assessment. $\mathcal{F} \mathrm{Am} \mathrm{Coll}$ Cardiol 1984; 3, 4: 1072-81.

5 Cohen M, Fuster V. What do we gain from the analysis of right ventricular function? $\mathcal{F}$ Am Coll Cardiol 1984; 3, 4: 1082-4.

6 Tajik AJ, Seward JB, Hagler DJ, Mair DD, Lie JT. Two dimensional real time ultrasonic imaging of the heart and great vessels: technique, image orientation, structure identification and validation. Mayo Clin Proc 1978; 53: 271-303.

7 Weyman AE. Cross sectional echocardiography. Philadelphia: Lea and Febiger, 1982: 497-504.

8 Report of the American Society of Echocardiography Committee on nomenclature and standards in two dimensional imaging. Circulation 1980; 62: 212-9.

9 Silverman NH, Schiller NB. Apex echocardiography. A two dimensional technique for evaluating congenital heart disease. Circulation 1978; 57: 583-7.

10 Lange LW, Sahn DJ, Allen HD, Goldberg SJ. Subxiphoid cross sectional echocardiography in infants and children with congenital heart disease. Circulation 1979; 59: 513.

11 Schnittger I, Gordon EP, Fitzgerald PJ, Popp RL. Standardised intracardiac measurements of two dimensional echocardiography. $7 \mathrm{Am}$ Coll Cardiol 1983; 2, 5: 934-8.

12 Hudson REB. Cardiovascular pathology. Vol 1. London: Edward Arnold, 1965: 15.

13 Bommer W, Weinert L, Newmann A, Neef J, Mason DT, Demaria A. Determination of right atrial and right ventricular size by two dimensional echocardiography. Circulation 1979; 60: 91-100.

14 Weyman AE. Cross sectional echocardiography. Philadelphia: Lea and Febiger, 1982: 382-95.

15 Watanabe T, Katsume H, Matsukobo H, Furukawa K, Ijichi $\mathrm{H}$. Estimation of right ventricular volume with two dimensional echocardiography. Am $\mathcal{F}$ Cardiol 1982; 49: $1946-53$.

16 Hiraishi S, Disessa TG, Jarmakani J, Nakanishi T, Isabel-Jones JB, Friedman WF. Two dimensional echocardiographic assessment of right ventricular volume in children with congenital heart disease. $A m \mathcal{F}$ Cardiol 1982; 50: 1360-75.

17 Starling MR, Crawford MN, Sorensen SG, O'Rourke RA. A new two dimensional echocardiographic technique for evaluating right ventricular size and performance in patients with obstructive lung disease. Circulation 1982; 66: 612-20.

18 Panidis I, Ren JF, Kotler MN, et al. Two dimensional echocardiographic estimation of right ventricular ejection fraction in patients with coronary artery disease. $\mathcal{F}$ Am Coll Cardiol 1983; 2, 5: 911-8. 
Br Heart $\mathcal{F} 1986 ; 56: 298$

Notices

\section{British Cardiac Society}

The Autumn Meeting will be held at the Wembley Conference Centre, London, on 25 to 27 November 1986, and the closing date for receipt of abstracts was 11 July 1986 .

The Annual General Meeting for 1987 will take place in Dundee on 8 and 9 April 1987, and the closing date for receipt of abstracts will be 6 January 1987.

\section{Aortic stenosis}

The European Society of Cardiology Working Group on Valvular Prostheses will be holding a congress at the Palais des Congres in Paris on 22 and 23 May 1987 on Aortic Stenosis in Adults-New Trends. Further information and registration forms from Professor J Acar, Hôpital Tenon, 4 rue de la Chine, 75980 Paris Cedex 20, France.

\section{Cardiac Doppler}

The 2nd International Congress on Cardiac Doppler will be held in Kyoto, Japan, from 25 to 29 November 1986. Further information from: Denise Liesse, Acting Secretary, ICDS, Department of Cardiology, Fondation A de Rothschild, 25-29 rue Manin, 75940 Paris, Cedex 19, France.

\section{Correction}

Echocardiographic measurement of the normal adult right ventricle $R$ Foale, $P$ Nihoyannopoulos, $W$ McKenna, A Kleinebenne, A Nadazdin, E Rowland, $G$ Smith - Dr Angelika Kleinebenne's name was misspelt in our July issue (p 33). 
taneous and completely independent, and possibly not the first reported.

William L Proudfit,

The Cleveland Clinic Foundation, 9500 Euclid Avenue,

Cleveland,

Ohio 44106,

USA.

\section{References}

1 Regulations and transactions of the Gloucestershire Medical Society. London: Royal College of Physicians.

2 Jenner E. Letter to Caleb H Parry, 1805. The Alan Mason Chesney Medical Archives, The Johns Hopkins Medical Institutions, Baltimore.

\section{Notices}

\section{British Cardiac Society}

The Annual General Meeting for 1987 will take place in Dundee on 8 and 9 April 1987, and the closing date for receipt of abstracts was 6 January 1987.

The Autumn Meeting will be held at the Wembley Conference Centre, London, on 24 to 26 November 1987, and the closing date for receipt of abstracts will be 10 July 1987 .

\section{Blood vessel imaging}

A residential course/workshop on Blood Vessel Imaging Using Ultrasound Techniques will be held at the Dolphin Hotel, Southampton on 11 to 13 May 1987. Details from: Mr K N Humphries, Blood Vessel Imaging Course, 5 Mossleigh Avenue, Rownhams, Southampton SO1 8FU.

\section{Correction}

Echocardiographic measurement of the normal adult right ventricle $R$ Foale, $P$ Nihoyannopoulos, $W$ McKenna, A Kleinebenne, A Nadazdin, E Rowland, $G$ Smith-The authors apologise for errors in their tables in this article published in the July issue (volume 56: pages 33-44). In tables 2, 3, 4, 5, and 6 1 SD should be shown; and in table 5 the value of 1 SD for absolute values $(\mathrm{cm})$ in rows $T 8$ and $T 10$ is 0.1 . 